\title{
. \\ THE PROGNOSIS OF CROHN'S DISEASE OF THE SMALL INTESTINE
}

\author{
J. M. Davis, M.ChIR., F.R.C.S. \\ Surgeon to the Whittington Hospital, London, N.19
}

Regional ileitis has only been widely recognized since the classical description by Crohn, Ginsberg and Oppenheimer in 1932. It is a rare diseasethe average general surgeon or physician will treat only one or two new cases each year. Consequently very few large series have yet been studied for periods of time long enough to allow a conclusive assessment of the prognosis. A most important aspect of the prognosis, the recurrence rate, has been very variably reported (Table I). Early series suggested that a recurrence followed surgery in about $15 \%$ of patients (Garlock and Crohn, 1945), but later series with longer periods of follow-up showed that this figure was an underestimate and that recurrence occurred in about $30 \%$ of patients (Crohn, 1958). Other reports containing patients followed for 10 to 15 years suggest that the long-term recurrence rate is much higher and is in the region of 60 to $80 \%$ (Van Patter, Bargen, Dockerty, Feldman, Mayo and Waugh, 1954; Cooke, 1955).

In this paper a further series of patients with Crohn's disease of the small intestine is reported to provide additional information about the prognosis. The results from this series and the reports from the literature are critically reviewed, the factors which may predispose to recurrence are examined and an attempt is made to explain some of the factors which may have led to such wide variations in the estimates of the recurrence rate.

\section{Present Series}

A retrospective survey has been made of all cases of Crohn's disease listed in the diagnostic indices of seven non-teaching hospitals and St. Mark's Hospital for Diseases of the Rectum during the years 1949 to $195^{8}$. With the exception of St. Mark's, these are all general hospitals serving an average cross section of the community. Altogether 263 cases were indexed as 'Crohn's disease', but I 12 cases have been excluded either because the diagnosis was inconclusive or because it fell into one of the controversial categories listed in Table 2. This left 151 cases of Crohn's disease of the small intestine, which form the main basis of this study.
TABLE I

Estimates of the Recurrence Rate of Crohn's Disease from the MOST Recent Literature

\begin{tabular}{|c|c|c|c|c|c|}
\hline \multicolumn{3}{|c|}{ Author } & $\begin{array}{c}\text { No. } \\
\text { Cases }\end{array}$ & $\mid \begin{array}{c}\text { Over- } \\
\text { all } \\
\text { Recur- } \\
\text { rence } \\
\text { Rate }\end{array}$ & $\mid \begin{array}{c}\text { Io- } \\
\text { Year } \\
\text { Recur- } \\
\text { rence } \\
\text { Rate }\end{array}$ \\
\hline $\begin{array}{l}\text { Crohn, } 195^{8} \\
\text { Mt. Sinai, N. }\end{array}$ & $\ddot{Y} \quad \cdots$ & • & 348 & $30 \%$ & $?$ \\
\hline $\begin{array}{l}\text { Van Patter and } \\
\text { Mayo Clinic }\end{array}$ & others, 195 & & 297 & $64 \%$ & $?$ \\
\hline $\begin{array}{l}\text { Marshall and } \\
\text { Lahey Clinic }\end{array}$ & Mathieson, & 1955 & 233 & $30 \%$ & $?$ \\
\hline $\begin{array}{l}\text { Jackson, I } 958 \\
\text { Mass. General }\end{array}$ & $\cdots \quad \ldots$ & . & 126 & $55 \%$ & ? \\
\hline $\begin{array}{l}\text { Gump and Le } \\
\text { Presbyterian, }\end{array}$ & $\begin{array}{l}\text { pore, } 1960 \\
V . Y \text {. }\end{array}$ & . & 97 & $40 \%$ & $43 \%$ \\
\hline $\begin{array}{l}\text { Cooke, r955 } \\
\text { Birmingham }\end{array}$ & $\cdots \quad \cdots$ & $\cdots$ & 83 & $45 \%$ & $78 \%$ \\
\hline $\begin{array}{l}\text { Pollock, r } 95^{8} \\
\text { Leeds }\end{array}$ & $\cdots$ & $\cdots$ & 71 & $?$ & $44 \%$ \\
\hline Present series & $\ldots$ & $\ldots$ & 120 & $31 \%$ & $?$ \\
\hline
\end{tabular}

TABLE 2 Final Diagnosis of 263 Cases Indexed as Crohn's

Cases included in present series: Chronic terminal ileitis...

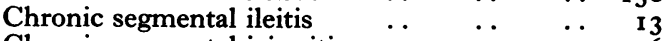

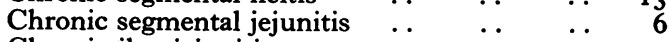

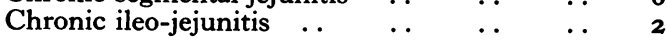

Cases excluded from present series: Acute terminal ileitis .. $\quad \ldots \quad \ldots \quad \ldots 40$

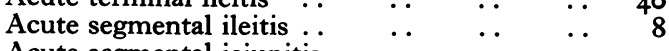

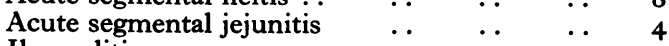

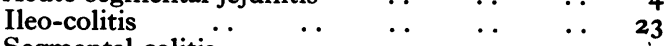
$\begin{array}{llllll}\text { Segmental colitis } & \ldots & \ldots & \ldots & \ldots & 23 \\ & \ldots & \ldots & \ldots & \ldots & \text { iI }\end{array}$

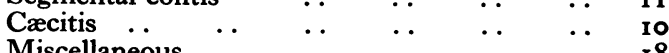
$\begin{array}{lllllll}\text { Miscellaneous } & \ldots & \ldots & \ldots & \ldots & \ldots & 10 \\ & & & & & & \end{array}$

These I 5 I cases of Crohn's disease of the small intestine have been followed up not only to determine the incidence of recurrence, but also to determine the general health of the patients regardless of the estimated activity of the intestinal 
lesion. Each patient has been examined by the writer whenever possible, but when this has not proved practical assessment has been made by a questionnaire from the patient or from a report from the patient's own doctor. Estimations of the hæmoglobin and the erythrocyte sedimentation rate have been performed routinely on all the patients examined, but X-rays of the gastrointestinal tract have only been performed when indicated on clinical grounds. Altogether $\mathrm{I}_{4} \mathrm{I}$ of I 5 patients have been traced: 16 patients have died, 82 patients have been assessed by examination and 43 patients have been assessed by questionnaire.

The diagnosis of recurrent or active disease has been made by consideration of the clinical, radiological and pathological evidence together with the operative findings. Histological sections have only been reviewed if the original report was inconclusive. In patients with negative or inconclusive $\mathrm{X}$-rays the diagnosis of recurrence was made entirely on clinical grounds and the following symptoms and signs were accepted as evidence of recurrent disease: Abdominal pain; diarrhœa more than four times a day (provided this was not the only symptom); palpable mass; internal or external abdominal fistulæ; loss of weight; elevated ESR. Four patients had radiological but no other evidence of recurrent disease and they have not been classified as having a recurrence.

Assessment of the general health of each patient on simple clinical grounds was much more straightforward than the diagnosis of recurrent disease and the following classification has been used:

(I) Good. Symptom free (excluding diarrhœa up to four times a day).

(2) Fair. Episodes of minor abdominal pain and diarrhœa not severe enough to interfere with regular work.

(3) Poor. Severe symptoms. Unable to perform regular work.

\section{Main Clinical Features}

(I) Age and Sex. In the present series the maximum incidence occurred in the third and fourth decades; the oldest patient was 72 years and the youngest was 14 years. The average age at the onset of symptoms was 32 years; this is slightly higher than the average age of most reported series, probably because of the exclusion of a large number of cases of acute ileitis, many of which occur in the younger age groups. The incidence in males and females was almost equal (females $5 \mathrm{I} \%$ ).

(2) Symptoms and Signs. The incidence of the symptoms and signs and the modes of presentation were very similar to those in most other series and they are shown in Table 3 .
TABLE 3

Main Symptoms and Modes of Presentation froow I 5 I Cases of Crohn's Disease of the Small Intestine

\begin{tabular}{llll}
\multicolumn{4}{c}{ Symptoms } \\
Abdominal pain & & $\ldots$ & 95 \\
Diarrhœea.. & $\ldots$ & $\ldots$ & 85 \\
Weight loss & $\ldots$ & $\ldots$ & 45 \\
Pyrexia .. & $\ldots$ & $\ldots$ & 31 \\
Fistula in ano & $\ldots$ & $\ldots$ & 21 \\
Amenorrhœe & $\ldots$ & $\ldots$ & 9 (of women) \\
Melæna .. & $\ldots$ & $\ldots$ & 3 \\
Delayed puberty & &. & 3
\end{tabular}

\section{Modes of Presentation}

\begin{tabular}{|c|c|c|}
\hline Abdominal mass & , & \\
\hline Intestinal obstruction & .. & \\
\hline Acute appendicitis'. & .. & \\
\hline Pelvic mass $\quad \ldots \quad \ldots$ & . & \\
\hline leo-rectosigmoid fistula & * & \\
\hline ncidental discovery.. & $\therefore$ & \\
\hline -vesical fistula & & \\
\hline er . . . . & & \\
\hline
\end{tabular}

(3) Incidence of New Cases and Relation to the Population. An average of 12 new cases a yeap have occurred over a Io-year period. This in cidence is almost certainly too low because the efficiency of the diagnostic indices varies frone hospital to hospital. If the three most reliafle indices, from hospitals serving a known population only are considered, then the probable incide of Crohn's disease of the small intestine is in the region of one new case a year in each 100,000 of the population.

(4) The Site of the Pathological Lesion. In $13 \%$ patients the lesion affected the distal ileum, ex 2 tending right down to the ileo-cæcal valve, an $\overrightarrow{5}$ they are classified under Crohn's original ter 3 minology as chronic terminal ileitis. Within this group nine patients had 'skip' lesions which were. not in continuity with the main disease process and affected either an isolated segment of upper ileunt. or of jejunum. In I I patients with chronic ter $\frac{5}{3}$ minal ileitis the disease extended to the cæcum but to no other more distal part of the large in testine. Patients with more extensive large bowel involvement have been classified as ileo-colitis and are excluded from the present series.

In the remaining 2 I patients the disease affected the proximal ileum or jejunum and they are classi $N$ fied as chronic segmental ileitis or jejunitis.

\section{Follow-up Findings}

(I) Mortality. There were 16 deaths from $14 \mathrm{~K}^{\circ}$ traced cases of Crohn's disease of the small in testine. Three deaths were due to unrelated inter $\frac{\mathbb{D}}{0}$ current disease and the remaining 13 deaths were directly attributable to Crohn's disease, giving of mortality of $9.8 \%$. Six of these 13 deaths occurreक 
at a late stage and were caused by recurrent or active disease; the remaining seven deaths followed surgical treatment of the primary lesion. Most of the operative deaths occurred in complicated cases-in two patients there was peritonitis due to perforation of the primary lesion and three patients died of sepsis following a secondary resection after a previous unsuccessful shortcircuiting operation. Only two deaths occurred following a primary resection in 75 patients $(2.7 \%)$.

The death rate of Crohn's disease is surprisingly low for a disease of such high morbidity. Most reported series have an overall mortality of 5 to $10 \%$. This low death rate is supported by the Registrar General's figures (I959)-during the previous to years in England and Wales the average number of deaths due to Crohn's disease a year was only 60 , or I per 750,000 population. If the annual incidence of new cases is, as suggested above, I per 100,000 of the population, and if the disease is not on the increase, then the ratio of new cases to deaths each year is $7.5: 1$. These figures suggest that only one person in seven or eight who develops Crohn's disease actually dies because of it.

(2) Duration of Follow-up. One hundred and forty-one patients have been traced from periods of six months to 29 years from the time of onset of the disease (Table 4). Many cases were first indexed in the period under review (1949-58), although they had originally been treated many years earlier, and several of these long-term cases only reappeared because they had developed recurrent disease or other complications.

(3) Recurrent Disease following Surgery. One hundred and twenty-seven patients were eventually treated by definitive surgery; there were seven operative deaths, leaving 120 cases available for study of the recurrence rate. Of these 120 patients, 37 have developed recurrent disease, giving an overall recurrence rate of $31 \%$, unrelated to the time of follow-up. Almost half of the total recurrences developed symptoms within two years of operation and the remaining recurrences occurred sporadically during the ensuing years (Table 5).

An accurate estimate of the long-term recurrence rate is not possible in the present series because
TABle 4

Period of Follow-up From ONSET OF SyMPTOMS OF i 4 I Cases of Crohn's Disease of the Small Intestine

\begin{tabular}{l|l|l|l|l|l|l|l|l|l}
\hline $\begin{array}{l}\text { Years } \\
\text { from } \\
\text { Onset }\end{array}$ & $0-1$ & $1-2$ & $2-3$ & $3-4$ & $4-5$ & $5-10$ & $10-20$ & $\begin{array}{c}\text { Over } \\
20\end{array}$ & Total \\
\hline Cases & ${ }_{14}$ & ${ }_{15}$ & ${ }_{18}$ & $I_{14}$ & ${ }_{17}$ & 43 & 16 & 4 & 141 \\
\hline
\end{tabular}

significant numbers of cases have not been followed for the longer periods of time. In addition, the statistical difficulties of interpreting a diminishing series are almost insurmountable. However, an attempt has been made to estimate the approximate long-term results by comparing an 'annual' recurrence rate with a 'pseudo cumulative' recurrence rate (Fig. I). The 'annual' rate is the number of recurrences that have been traced up to the period under consideration expressed as a percentage of the total number of cases followed to the same period. The figures for this series at two, five and 10 years are $16 \%, 17 \%$ and $36 \%$ respectively. This incidence is almost certainly an underestimate of the true long-term rate because many of the short-term patients with recurrent disease have not yet been followed to the later years. The 'pseudo cumulative' recurrence rate includes these short-term recurrences and is an attempt to relate them to the total numbers of patients followed to the later periods. It has been calculated by expressing the number of recurrences followed up to and before the period under consideration as a percentage of the sum of the same figure of recurrences added to the number of nonrecurrences who have been followed for the whole length of the same period. A true cumulative recurrence rate for a diminishing series is impossible because as time progresses the number of recurrences outnumber the total of traced cases and the rate exceeds $100 \%$.

It must be stressed that the 'pseudo cumulative' recurrence rate is an artificial figure which overestimates the true recurrence rate. Nevertheless, it allows a useful comparison with the ' annual' recurrence rate, because in a perfect series, with every case followed for the maximum period of time, these two rates would coincide.

TABLE 5

Follow-up Periods of izo Patients Treated by Definitive Surgery and time of Onset of Recurrent Disease

\begin{tabular}{|c|c|c|c|c|c|c|c|c|c|c|c|c|c|c|c|c|}
\hline \multicolumn{3}{|c|}{$\begin{array}{l}\text { Years from } \\
\text { Operation }\end{array}$} & \multirow{2}{*}{$\frac{0-1}{13}$} & \multirow{2}{*}{$\frac{1-2}{16}$} & \multirow{2}{*}{$\frac{2-3}{17}$} & \multirow{2}{*}{$\frac{3-4}{9}$} & \multirow{2}{*}{$\frac{4-5}{17}$} & \multirow{2}{*}{$\frac{5^{-6}}{\text { II }}$} & \multirow{2}{*}{$\frac{6-7}{9}$} & \multirow{2}{*}{$\frac{7-8}{5}$} & \multirow{2}{*}{$\frac{8-9}{3}$} & \multirow{2}{*}{$\frac{9-10}{6}$} & \multirow{2}{*}{$\frac{10-15}{6}$} & \multirow{2}{*}{$\frac{15-20}{5}$} & \multirow{2}{*}{$\begin{array}{c}\begin{array}{c}\text { Over } \\
20\end{array} \\
3\end{array}$} & \multirow{2}{*}{$\frac{\text { Total }}{120}$} \\
\hline Cases & . & . & & & & & & & & & & & & & & \\
\hline \multicolumn{3}{|c|}{ Onset rẹcurrence. . } & I I & 7 & 3 & 3 & I & 2 & 3 & 2 & $\mathbf{I}$ & 0 & 2 & 0 & 2 & $\begin{array}{c}37 \\
(31 \%)\end{array}$ \\
\hline
\end{tabular}

Note.-Deaths following initia loperation are excluded. 
Consequently, if these two estimates are plotted on a graph, the truth must lie somewhere between them, and for this series the figures suggest that the true recurrence rate is in the region of $25 \%$ at five years and $45 \%$ at Io years (Fig. I).

(4) Active Diseases following Conservative Treatment. Although 48 of ${ }_{14} \mathrm{I}$ traced cases were first treated conservatively, the majority eventually came to surgery, leaving only I 4 patients treated entirely without operation (laparotomy without definite surgery is counted as conservative treatment). Of these I4 patients treated conservatively, two died of active disease and two were severely incapacitated by the disease; the remaining 10 patients remained reasonably well, nine of them having been followed up for more than four years.

Conservative treatment is considered to have failed, either because surgery had become necessary or because the condition of the patient had deteriorated, in $54 \%$ of patients at two years and $94 \%$ at ro years (Fig. 2). The overall medical salvage rate of about $10 \%$ is similar to that of most series, although this estimate is possibly now on the low side because in recent years the indications for surgical treatment have probably become more stringent.

(5) Clinical State Regardless of Active or Recurrent Disease. The general health of each patient has been assessed as good, fair or poor by consideration of the simple criteria described earlier. This assessment has been made at the end of the follow-up period except for patients who died of unrelated intercurrent disease when assessment was made from the period preceding the terminal illness. The results of this assessment of the clinical state of the whole series of I I I patients are: good $51 \%$, fair $27 \%$, poor $13 \%$, died $9 \%$. It is surprising that only just over one-fifth of the patients have either been classified as poor or have died as a direct result of the disease.

Comparison of the overall recurrence rate and the clinical state of the 120 patients treated by definitive surgery shows that, whereas $31 \%$ of patients developed recurrent disease, only $18 \%$ of patients were incapacitated or had died of the disease (Fig. 3). This difference is explained partly because several patients with recurrent disease suffered from relatively few symptoms and also because a small number of patients had apparently been cured by a second operation. This discrepancy between the estimates of the recurrence rate and the clinical state has also been noted by Cooke (1955), who reports a surprisingly low rate of invalidism in his series despite an overall recurrence rate of $45 \%$ and Io-year recurrence rate of $78 \%$. In recent years so much attention has been focused on the problem of the recurrence rate that there has been a tendency to overlook the
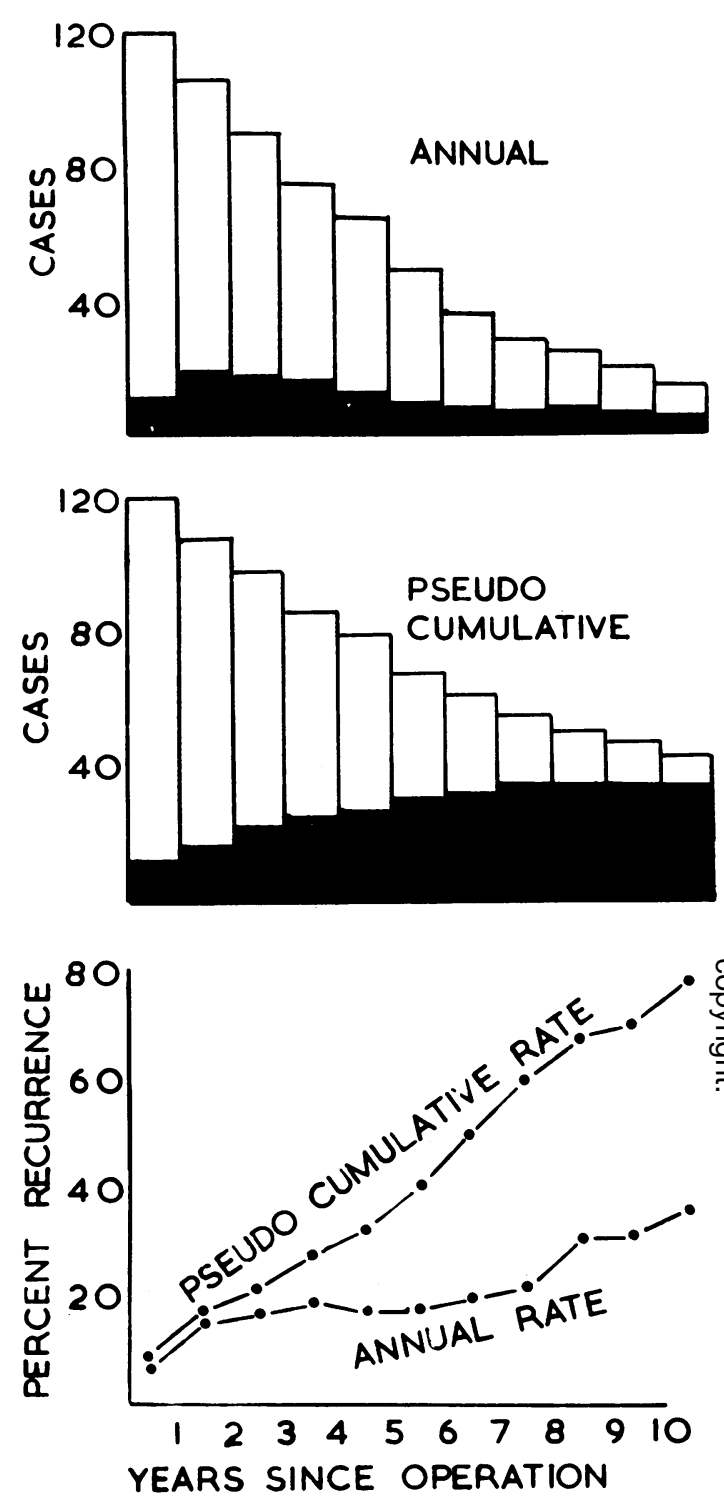

FIG. I.-Two methods of expressing recurrence rate from 120 patients after surgery. Recurrences are shown in black. See text for explanation of the terms ' annual ' and 'pseudo-cumulative'.

very important fact that 70 to $80 \%$ of patients remain surprisingly well for long periods of time.

Factors which may Predispose to Recurrence

The following factors which may predispose to recurrent disease have been examined:

(1) Extent of the Intestinal Lesion. This is probably the only important single factor which may be of help in predicting the likelihood of recurrence in any individual case-the more extensive the 


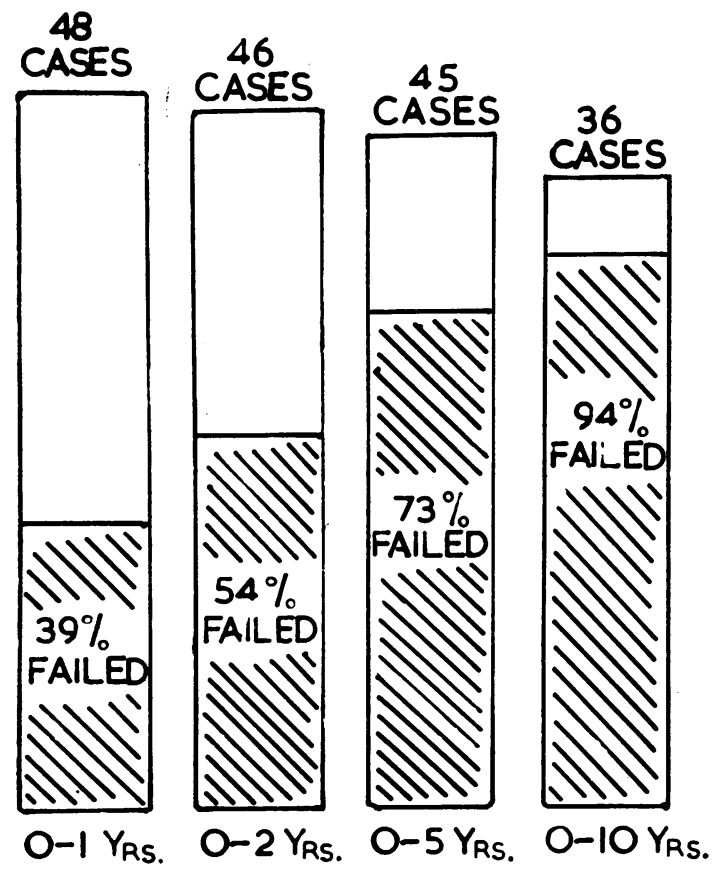

FIG. 2.-Failure rate of conservative treatment from 48 patients.

disease the greater the chance of recurrence. In the present series the extent of the lesion was recorded accurately in only 74 patients; the average length of the diseased intestine in the patients who did not develop a recurrence of the disease was I I in., as compared with 19 in. in the patients who did develop a recurrence. Van Patter and others (1954) have reported similar findings.

'Skip' lesions do not seem to carry a particularly bad prognosis. From the nine patients in which a 'skip' lesion occurred in the present series only two developed recurrent disease; seven of the 'skip' areas were resected en bloc with the main lesion and two were resected separately. One of the recurrences occurred at the site of separate resection.

Cooke (1955) has drawn attention to the high incidence of recurrence in the patients who have been found to have steatorrhœa before operation. He suggests that steatorrhœa indicates an extensive intestinal lesion and consequently a greater risk of recurrence. In the present series fæcal fat estimations have only occasionally been performed prior to operation and therefore there is no further information about what is probably a most useful prognostic guide.

(2) Choice of Operation. There are three main operations which can be performed for Crohn's disease of the small intestine-resection, a nondefunctioning short-circuiting operation and a

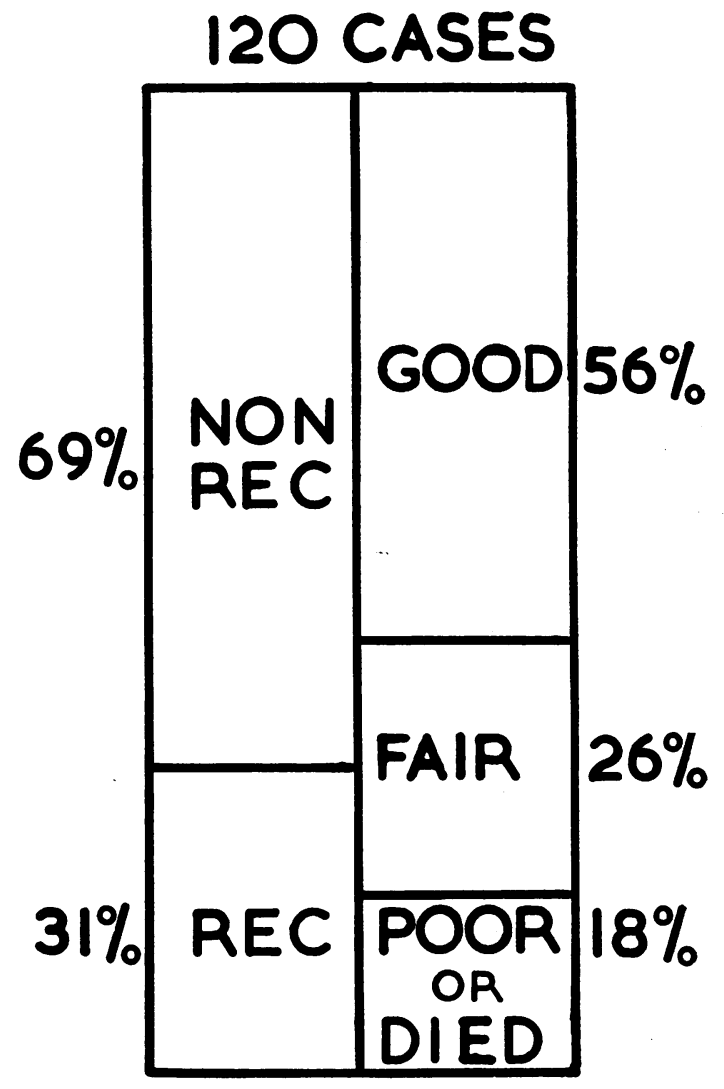

FIG. 3.-Comparison of the overall recurrence rate with . the clinical state from 120 patients after surgery.

defunctioning short-circuiting operation. It is most important to distinguish between the two forms of short-circuiting procedure, the essential difference being that in the defunctioning type the bowel is completely divided and the distal end is oversewn to leave a blind loop, thus excluding the diseased area from the main intestinal stream (Fig. 4). In the present series just over two-thirds of the patients were treated by primary resection and the remainder were treated by a shortcircuiting operation; only I I patients were treated by a defunctioning short-circuiting operation as a primary procedure.

Accurate comparison of the incidence of recurrence after the three types of operation is not possible in the present series because the numbers of the sub-groups are too small to be significant, but the trend strongly supports the conclusion of the Mayo Clinic (Van Patter and others, 1954) that the incidence of recurrence bears no relation to the type of operation performed. However, the morbidity following short-circuiting operations was very high, particularly after the non-defunctioning procedures; in the present series almost 


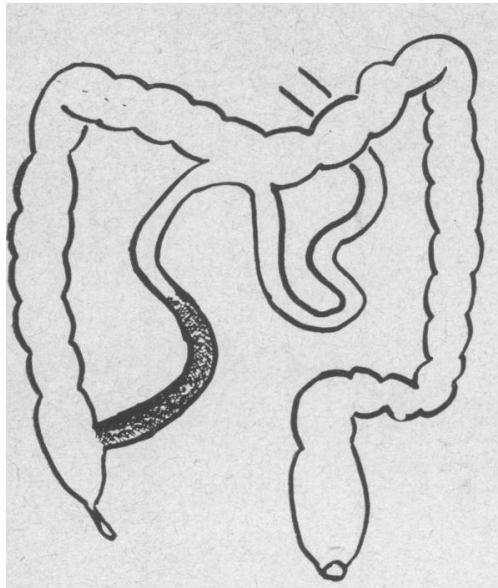

SHORT CIRCUIT WITHOUT EXCLUSION

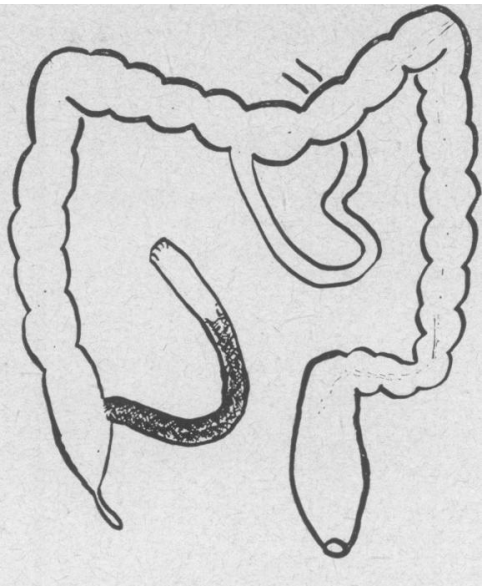

SHORT CIRCUIT WITH EXCLUSION
FIG. 4--Two types of short-circuiting operation-non-defunctioning without exclusion and defunctioning with exclusion. one-third (eight of 26 cases) treated by this operation subsequently required resection, not for recurrent disease, but for persistent local or systemic symptoms. The morbidity after defunctioning operations was not quite so high, but two of the II patients treated by this method developed mechanical loop complications; one patient developed intussusception of the blind loop and another patient developed a closed-loop obstruction. Garlock and Crohn (1945), who are strong protagonists of the defunctioning short-circuiting operation because it carries a low mortality, admit that from 90 patients treated by this method 25 $(27 \%)$ eventually required resection for persisting symptoms at the original site of the disease.

It is concluded that resection is now without doubt the treatment of choice. The main original objection to resection, that it carried an operative mortality in the region of $14 \%$ (Crohn, 1958), has been rendered invalid by improved operative technique and improved pre- and post-operative care. Even in the present series, drawn mainly from non-teaching hospitals, there were only two operative deaths following primary resection in 75 uncomplicated patients (patients with perforation of the ileum have been excluded). The majority of specialized centres now confirm an even lower mortality. However, there are times when resection may be considered inadvisable, either because of the patient's general condition or because of dense adhesions or gross thickening of the mesentery and, under these circumstances, a defunctioning short-circuiting operation is considered to be a reasonable alternative. The nondefunctioning short-circuiting operation has been very justly condemned by Lewisohn (1938) and it should be reserved only as a temporary expedient in obstructed cases-with modern instruments for intestinal decomipression at the time of operation (Savage, 1960) this operation should now rarely be necessary.

(3) Extent of Excision. Van Patter and others (1954) found no correlation between the recurrence rate and the length of normal intestine proximaB to the diseased area in the specimens of patients treated by resection. In the present series too fer specimens have been measured accurately $t \sigma+$ decide whether a radical excision reduces the risk of recurrence. This is a point of great importance to the surgeon - on the one hand, a very extensive operation is no guarantee against recurrence and may in itself cause malabsorption-on the other hand, the pathological process sometimes proves to be more extensive than has been apparent at the time of operation and recurrence is almost inevitable if resection is performed through diseased intestine. In the present series five patients were found to have disease extending right up to the line of section and four developed symptoms of recurrent disease within six months. A reasonable compromise has been suggested by Crohn (1958), who advocates section of the bowel 12 in. proximal to the apparent upper limit of the disease.

(4) Duration of Symptoms Prior to Surgery. Pollock (1958) suggests that the risk of recurrence is greater in patients who have a long history prior to operation. He gives a Io-year recurrence rate of $75 \%$ from eight cases of 'chronic' Crohn's disease (history over two years), as compared with a recurrence rate of $20 \%$ from Io cases of ' subacute ' Crohn's disease (history one month to two years). These figures are really too small to be significant and they conflict with Crohn's view 
that the greatest percentage of cures comes from the patients in which operation has been postponed for about two years. In fact, Crohn (1958) advocates delaying operation for about this period of time ' until the inflammatory process has cooled off and healing resolution has begun'. In the present series there was no significant correlation between the recurrence rate and the length of the pre-operative history $-46 \%$ of recurrences had a history of more than two years compared with $4 \mathrm{r} \%$ of non-recurrences.

In practice the timing of the operation is usually dictated by the patients' symptoms and few individual patients pass through a series of predictable phases. However, exacerbations of the disease, probably caused by episodes of secondary acute inflammation, will usually resolve if treated conservatively. It is probably wise to avoid operating during these episodes because the acute inflammation may obscure the extent of the underlying granulomatous process and so make it difficult for the proximal extent of the lesion to be defined.

(5) Age and Sex. In the present series slightly more females developed recurrence than males. Females, 2 I cases; males, 16 cases. This difference is not significant.

The age distribution of the patients who developed recurrent disease shows no marked difference from that of the whole series. The older age groups were not relatively immune, as has been suggested by Jackson (1958), as seven of the recurrences were over the age of 40 at the time of onset of the disease.

\section{Factors which Influence Estimates of the Recurrence Rate}

The estimate of the recurrence rate for any given series of Crohn's disease is influenced by variations of definition, selection and interpretation. The data from any series can be manipulated in several different ways to give divergent results. If, for example, the patients from the present series who had been followed for less than two years had been eliminated, and if the patients with symptomless radiological ' recurrences' had been accepted as clinical recurrences, then the overall recurrence rate would have risen from 31 to $43 \%$. Consequently, it is very important to examine carefully all the factors concerned before accepting the recurrence figures for any given series. These various factors are discussed in turn with reference to the present series and to other reported series, where relevant.

(I) Definition of 'Recurrence'. In the present series 'recurrence' is used only to denote a new chronic granulomatous lesion developing in patients treated either by resection or by one of the two types of short-circuiting operation. Failure of resolution or recrudescence of the primary lesion after one of the short-circuiting operations has not been classified as recurrent disease. The only form of recurrence recognized after this type of operation has been a new lesion in the ileum proximal to the anastomosis or a spread of the disease to the large intestine.

The definition of ' recurrence' in the literature is very variably defined and its meaning is not always restricted to patients who have received some form of definitive surgery, but is also used to include failures of conservative treatment and exacerbations of the disease in patients who have only received a laparotomy or an appendicectomy. Used in this sense ' recurrence ' loses its true meaning of 'recurrence following definitive surgery' and gives artificially high figures.

(2) Selection of Cases. One of the main problems in analysing any series of Crohn's disease is to decide whether or not to include two large categories of patients-acute ileitis and Crohn's disease of the large intestine. Inclusion of the former will influence estimates of the prognosis favourably and inclusion of the latter will have the converse effect.

Acute ileitis in the present series has been excluded if the history has not been longer than seven days. The relationship of acute ileitis to Crohn's disease has been controversial, but the weight of evidence now strongly suggests that if the history is short this condition only very rarely progresses to form the chronic granulomatous lesion. There may well be two forms of acute ileitis, one being a separate disease entity with a good prognosis and the other being genuine Crohn's disease, which has given only minor symptoms until an episode of secondary acute infection has become superimposed on the underlying chronic granulomatous lesion. In retrospect the main distinguishing feature between these two forms of acute ileitis is the length of the history. Fifty-two patients with a short history of acute ileitis have been excluded from the present series because 42 of this group have been traced and only one has developed symptoms suggesting a chronic granulomatous lesion (Table 6). In comparison, 23 patients of acute ileitis with a history of more than a week have been traced and are included in the present series because 17 have progressed to give definite signs of a chronic granulomatous lesion. Several recent authorities have adopted a similar policy: Pollock (1958) distinguishes acute Crohn's disease with a history of less than one month and Gump and Lepore (1960) have excluded a large group of cases presenting with symptoms suggestive of acute appendicitis.

Crohn's disease of the large intestine constitutes the second main problem of selection. Twenty- 
TABLE 6

The Effect of the Length of the History on the Prognosis of 75 Cases of Acute Ileitis

\begin{tabular}{c|c|c|c|c}
\hline History & $\begin{array}{c}\text { Acute } \\
\text { lleitis } \\
\text { Cases }\end{array}$ & Traced & Died & $\begin{array}{c}\text { Developed } \\
\text { Chronic } \\
\text { Lesions }\end{array}$ \\
\cline { 1 - 3 } $\begin{array}{r}\text { Less than } \\
7 \text { days.. }\end{array}$ & 52 & 42 & 2 & I $(2 \%)$ \\
\hline $\begin{array}{r}\text { More than } \\
7 \text { days.. }\end{array}$ & 23 & 23 & 0 & $17(73 \%)$ \\
\hline
\end{tabular}

three patients with ileo-colitis (histological Crohn's disease of the terminal ileum associated with diffuse or segmental lesions of the large intestine) have been excluded from the present series (Table 2). The main reason for their exclusion is that the diagnosis of Crohn's disease in these patients has often only been established in retrospect after many years of various forms of management and multiple piecemeal operations. Recurrence after surgery for ileo-colitis appears common, but many failures appear to have been due to limited resections through diseased tissue and it would only confuse the picture of the overall prognosis to include this group together with Crohn's disease of the small intestine. However, four cases of ileo-colitis have been included in the present series because the ileal lesion preceded the large gut lesion by one or more years: in these patients the colitis was clearly a complication of the small gut lesion and they have been classified as having recurrent disease. Many of the reported series contain cases that would fall into the category of ileo-colitis and thus increase the recurrence figures.

(3) Criteria of Recurrent Disease. Histological proof of recurrent disease was only obtained in about half of the cases of the present series. In the remaining cases the diagnosis of recurrence was made on clinical and radiological grounds and was usually straightforward, but in a few cases this diagnosis was very difficult and sometimes impossible to establish with certainty. This small proportion of doubtful cases may be interpreted by one observer as recurrent disease and as nonrecurrent disease by another, depending on the criteria accepted. Although only a small number of cases are involved, they may be enough to influence the recurrence figures in a small series by 10 to $15 \%$. This lack of an absolute standard of what constitutes a clinical recurrence probably accounts for the main differences of opinion about the incidence of recurrent disease.

There are two main difficulties. The first is the problem of the patient with diarrhœa but with no other symptoms or confirmation of recurrent disease. Whilst it is true that diarrhœa is usually the first symptom of recurrence, it is very common after resection or exclusion of the terminal ileum and it is probably caused by the loss of an im portant area of water-absorbing intestinal mucosa In this series diarrhœa alone has not been accepted. as evidence of recurrent disease.

The second difficulty is the problem of the patient who is free of symptoms, but who has radiological changes suggestive of recurrence Dyson, Hodes and Rhoades (1954) first drew attention to this dilemma and suggested that minon abnormalities of the intestinal mucosa and dila $=$ tion of the intestine might be associated merely $\vec{P}$ with deformity in the region of the anastomosis $\overrightarrow{\vec{\omega}}$ but Van Patter and others (1954) think that X-raye signs may precede a clinical recurrence. In the present series there have been five symptomless. patients with doubtful X-ray findings and theje have not been classified as recurrence. Cook $\phi$ (1955) partly attributed his high recurrence rate to the inclusion of several symptomless radiologicat recurrences.

(4) Duration of the Period of Follow-up. In the present series almost half of the patients who recurred after surgery developed the symptoms of recurrent disease within two years of operation After two years the risk of recurrence diminishes but it is always present-one patient developed the symptoms of recurrence 29 years followisg the initial operation. Consequently the lengthspop the period of follow-up is a most important factor in assessing the overall recurrence rate. Lowb recurrence figures from the early reports were un doubtedly mainly due to the small number of long term cases. Even now very few series, including the present one, contain enough long-term cases to form a conclusive assessment of the long-term $\overrightarrow{\vec{B}}$ recurrence rate.

The high overall recurrence rate of $64 \%$ re ported by the Mayo Clinic (Van Patter and others? 1954) at first sight appears to be due to the large number of long-term cases in this series. However examination of the data shows that an unusuallyg high proportion of recurrences, almost threequarters, developed symptoms within two years of operation. Therefore this high recurrence rate cannot be explained only by the large number of long-term cases and there must be some other reason to account for the unusually high incidence of early recurrences. The most likely explanations is that the criteria accepted for the diagnosis of recurrent disease by the Mayo Clinic has been different from that of most other series.

(5) Statistical interpretation. There are severa的 difficulties in assessing the long-term recurrence rate of Crohn's disease not only because the totap numbers of cases in most series are small by statistical standards, but also because the numbers of cases followed inevitably decrease with time and 
the results from a diminishing series can be interpreted in several different ways. It has been seen from the follow-up results of the present series that there are several methods of expressing the long-term recurrence rate and that any estimate of the figures at ro years can be no more than an intelligent guess. The main reasons are that this series is not only overloaded with an unrepresentative selection of long-term cases, but it also contains a high proportion of short-term cases, many of which have recurred but have not yet been followed to the later years. Most series contain the same statistical difficulties and most longterm figures should be viewed tentatively.

It is noteworthy that in the two largest series (Crohn, 1958; Van Patter and others from the Mayo Clinic, 1954) there has been no attempt to give definite figures for the long-term recurrence rate, presumably because of the statistical difficulties. Cooke (1955) has tried to calculate the longterm recurrence rate from the Mayo Clinic data and estimates a $68 \%$ and $80 \%$ recurrence rate at Io and 15 years for this series. It is difficult to determine how these estimates have been made, because the necessary data are not available in the Mayo Clinic report to reach these conclusions. These high figures may reflect a ' pseudo cumulative' result, but they cannot reflect the proportion of recurrences present in patients followed for 10 and $I_{5}$ years. Cooke (1955) has estimated his own long-term results 'on the same basis' as $78 \%$ at Io years.

Gump and Lepore (1960) in a series of 97 cases followed for Io or more years report a ' cumulative' recurrence rate of $43 \%$ at Io years, which dimin- ishes to $40 \%$ by 15 years. Whilst agreeing with their general hypothesis that the recurrence rate over 10 years does not approach $100 \%$, it is difficult to accept this anomalous result. There can obviously be no absolute diminution of the true recurrence rate with the progression of time and this surprising finding is probably best regarded as a statistical curiosity.

\section{Summary}

A series of 14I cases of Crohn's disease of the small intestine have been followed for varying periods. The main conclusions are:

(I) The overall recurrence rate after surgery is $31 \%$ (120 cases).

(2) The failure rate with conservative management is $94 \%$ ( 48 cases).

(3) Primary resection is the operation of choice.

(4) Consideration of the recurrence figures alone gives an inaccurate picture of the overall prognosis.

(5) Estimates of the long-term recurrence rate are fraught with difficulties of definition, selection and interpretation and they should be viewed very critically.

I am very grateful to the physicians and surgeons of the following hospitals for allowing me to follow up their patients: Addenbrooke's, Cambridge; Ashford, Middlesex; Central Middlesex; Chase Farm, Middlesex; Edgware General, Middlesex; St. Mark's, London; West Middlesex; Whittington, London.

I am also very grateful for financial assistance from the Department of Gastroenterology, Central Middlesex Hospital, and the Research Department, St. Mark's Hospital.

\section{REFERENCES}

Cooke, W. T. (1955): Nutritional and Metabolic Factors in the Ætiology and Treatment of Regional Ileitis, Ann. roy. Coll. Surg. Eng., 17, 137.

Crohn, B. B., Ginsburg, L., and Oppenheimer, G. D. (1932): Regional Ileitis: A Pathologic and Clinical Entity, F. Amer. med. Ass., 99, 1323.

(1958): ' Regional Ileitis'. New York: Grune and Stratton.

Dyson, W. L., Hodes, P. J., and RHOADES, J. E. (1954): Late Results in the Surgical Treatment of Regional Enteritis, Penn. med. F., 57, 443 .

GARLOCK, J. H., and CROHN, B. B. (1945): An Appraisal of the Result of Surgery in the Treatment of Regional Ileitis, F. Amer. med. Ass., 127, 205.

Gump, F., and LePORE, M. L. (1960): Prognosis in Acute and Chronic Regional Enteritis, Gastroenterology, 39, 694.

JaCkson, B. B. (1958): Chronic Regional Enteritis, Ann. Surg., 148, 81.

LEWISOHN, R. (1938): Segmental Enteritis, Surg. Gynec. Obstet., 66, 215.

Marshall, S. F., and Mathieson, W. L. (1955): Surgical Treatment of Chronic Regional Enteritis, Lahey Clin. Bull., 9,66 .

Pollock, A. V. (1958): Crohn's Disease, Brit. F. Surg., 197, 193.

Registrar General's Statistical Review of England and Wales for the Year i959: Part I, 29.

Savage, P. J. (1960): The Management of Acute Intestinal Obstruction, Brit. F. Surg., 47, 643.

Van Patter, W. N., Bargen, J. A., Dockerty, M. B., Feldman, W. H., Mayo, C. W., and Waugh, J. M. (1954): Regional Enteritis, Gastroenterology, 26, 347. 